\title{
A POSSIBILIDADE DE FLEXIBILIZAÇÃO DAS REGRAS IMPEDITIVAS DA ADOÇÃO PARA ATENDER A CASOS PECULIARES: ADOÇÃO POR AVÓS E TIOS ${ }^{1}$
}

\author{
Enio Gentil Vieira Júnior ${ }^{2}$
}

Resumo: Trata o presente artigo da análise da possibilidade jurídica, conforme interpretação teleológica, de "adoções peculiares", a primeira vista vedadas pelo Estatuto da Criança e do Adolescente. A pesquisa, que teve em conta a doutrina e jurisprudência concernente ao direito da criança e do adolescente, evidencia incompatibilidade de tais vedações, se consideradas "totais" ("absolutas") com o restante do contexto da legislação de regência, mormente quando considerados a proteção integral, o melhor interesse e a condição peculiar de sujeitos em desenvolvimento como norte interpretativo.

Palavras-chave: Adoção por avós e tios. Família extensa. Adoção unilateral. Interpretação teleológica.

\section{INTRODUÇÃO}

$\mathrm{O}$ art. 43 do Estatuto da Criança e do Adolescente define aquela que deveria ser a única regra relativa à adoção, ao mencionar que tal medida "será deferida quando apresentar reais

1 Artigo científico apresentado no III Congresso Nacional dos Defensores Públicos da Infância e Juventude. Belém/PA. Setembro/2012.

2 Advogado da Infância e Juventude e Professor das Escolas Superiores da Magistratura e da Advocacia do Estado de Santa Catarina. E-mail: eniogentil@tjsc.jus.br 
vantagens para o adotando e fundar-se em motivos legítimos". Todos os demais regramentos relativos à adoção, numa interpretação garantista ${ }^{3}$, ou melhor, progressista deveriam ser considerados "acessórios" e, portanto, passíveis de relativização quando, diante do caso concreto, conflitantes com a mencionada "norma-princípio".

Nas linhas que sequem, buscar-se-á demonstrar que toda e qualquer tentativa de impedimento à adoção, como a diferença mínima de idade entre adotante e adotando (art. 42, § 30 , do Estatuto), a vedação de adoção por avós e irmãos (art. 42, § 1\%), a obrigatoriedade de adoção por pessoas casadas ou que mantenham união estável ou as limitações da adoção unilateral (art. $42, \S \S 2^{\circ}$ e $4^{\circ}$ ), frente à norma do art. 43 , representam intervenções, no mínimo injustas ${ }^{4}$, que impedem, na maioria das vezes, a formalização de situações já consolidadas da realidade.

Assim como já decidiu o Superior Tribunal de Justiça, ao tratar da adoção de uma criança formulada por casal homoafetivo, situação que já se deve ter como superada, consolidada, certas barreiras, sobretudo as culturais, devem ser enfrentadas, e muitas vezes superadas, pelos atores do direito. ${ }^{5}$

3 Parece que a doutrina tem lembrado das garantias constitucionais somente quando da questão infracional. No entanto, convém mencionar que as questões relativas à infância e juventude encontram-se num mesmo contexto, em geral de desconhecimento da condição do sujeito-criança/adolescente como titular de direitos, de personalidade.

4 Ensina Rodrigo da Cunha Pereira, em artigo intitulado Direito , Amor e Sexualidade: "Cada julgador, com seus valores e concepções morais, é quem faz uma sentença. (...) Mas isso não tem nada de mais. Nem de novo, nem de velho. Os julgamentos sempre foram e continuarão sendo assim. A novidade é apenas o reconhecimento da subjetividade na objetividade. Em outras palavras: a partir do momento em que o Direito deixar de negar que os atos e fatos objetivos são perpassados pelo inconsciente e reconhecer a legalidade da subjetividade, poderemos estar mais próximos do ideal de Justiça. (in.: http://www.gontijo-familia.adv. br/2008/artigos_pdf/Rodrigo_da_Cunha/DireitoAmorSexo.pdf)

5 Recurso Especial n. 889.852-RS̄: "2. Em um mundo pós-moderno de velocidade instantânea da informação, sem fronteiras ou barreiras, sobretudo as culturais e as relativas aos costumes, onde a sociedade transforma-se velozmente, a interpretação da lei deve levar em conta, sempre que possível, os postulados maiores do direito universal. 3 . $\mathrm{O}$ artigo $1^{\circ}$ da Lei $12.010 / 09$ prevê a 'garantia do direito à convivência familiar a todas e crianças e adolescentes'. Por sua vez, o artigo 43 do ECA estabelece que 'a adoção será deferida quando apresentar reais vantagens para o adotando e fundar-se em motivos legítimos'." 


\section{DESENVOLVIMENTO}

O presente artigo científico parte do pressuposto de que a adoção sempre poderá ser deferida se representar reais e indiscutíveis vantagens ao adotando, cabendo, portanto, a flexibilização de qualquer dispositivo que, eventualmente, pudesse parecer espécie de "vedação total" à medida. Como diz Rodrigo da Cunha Pereira: "o Direito é dinâmico, deve traduzir a realidade social e não pode ficar apegado à literalidade da lei”. ${ }^{\text {? }}$

De início, cabe também mencionar que se opta pelo critério teleológico ${ }^{8}$ ou sociológico de interpretação dos dispositivos do Estatuto da Criança e do Adolescente. Não parece ter sido outra a intenção do legislador ao se inspirar no art. $5^{\circ}$, da Lei de Introdução ao Código Civil ${ }^{9}$ quando da elaboração do art. $6^{\circ}$ do Estatuto, seu "norte" interpretativo.

Mencionado dispositivo estabelece que o Estatuto deve ser interpretado conforme os fins sociais a que se dirige, as exigências do bem comum, os direitos e deveres individuais e coletivos, e a condição peculiar da criança e do adolescente como pessoas em desenvolvimento.

Luciano Alves Rossato afirma que os parâmetros presentes no art. $6^{\circ}$ do Estatuto, tratam-se de "cláusulas abertas"10, que,

6 Terminologia utilizada por Galdino Augusto Coelho Bordallo na obra "Curso de Direito da Criança e do Adolescente. Aspectos Teóricos e Práticos".

7 Rodrigo da Cunha Pereira, in.: http://www.gontijo-familia.adv.br/2008/artigos_pdf/ Rodrigo_da_Cunha/DireitoAmorSexo.pdf

8 Conforme ensinamentos de Válter Kenii Ishida, in Estatuto da Criança e do Adolescente. Doutrina e Jurisprudência (pg. 11): "Neste sentido, o STJ: "Na linha de precedente desta Corte, a legislação que dispõe sobre a proteção à criança e ao adolescente proclama enfaticamente a especial atenção que se deve dar aos seus direitos e interesses e à hermenêutica valorativa e teleológica na sua exegese" (RSTJ 120/341)

9 Decreto-Lei n. 4.657/1942 (Lei de Introdução às normas do Direito Brasileiro): "Art. 50 Na aplicação da lei, o juiz atenderá aos fins sociais a que ela se dirige e às exigências do bem comum."

$10 \mathrm{Na}$ obra Estatuto da Criança e do Adolescente Comentado, Luciano Alves Rossato explicita: "Note-se que se está diante de cláusulas abertas, que deixam ao intérprete o mister de complementa o seu sentido. O primeiro critério enunciado pelo legislador exige interpretação segundo os fins sociais a que o Estatuto se dirige. Nesse sentido, devem os operadores do direito trabalhar com exegese que considere crianças e adolescentes como sujeitos de direitos e que gozam de proteção especial que lhes confira prioridade gente às situações comuns que en- 
evidentemente, encarregam o intérprete da tarefa de complementar o seu sentido, seu conteúdo. De fato, uma lei expressamente inspirada no "princípio da proteção integral" não poderia, ao menos em tese, comportar normas que enrijecessem a sua aplicação/efetivação.

Do contrário, o Estatuto para que se possa efetivar depende de interpretação flexível, que adeque seus dispositivos à realidade, ao "bem da vida". Caso contrário, voltar-se-ia a repetir os tempos de Direito Tutelar, em que respostas rígidas, pouco variadas, e nada criativas, muito mais violavam do que promoviam os direitos de crianças e adolescentes.

Tanto é verdade, que mesmo a mais tradicional linha doutrinária considera que as medidas de proteção previstas no art. 101 do Estatuto da Criança e do Adolescente, tratam-se de rol meramente exemplificativo. O Estatuto abre a possibilidade de aplicação de outras medidas, construídas casuisticamente, em pelo menos dois momentos: a) no próprio art. 101, caput, onde consta a expressão "dentre outras, as seguintes medidas"; b) quanto estabelece no art. 102 a regularização do registro civil como medida a acompanhar as de proteção previstas no dispositivo anterior.

Para o presente estudo, cabe, desde já, a importante consideração de que o legislador, ao que parece, pretendeu flexibilizar as normas do Estatuto da Criança e do Adolescente, prevendo que a sua justa aplicação dependeria da análise do caso concreto, com soluções peculiares a cada situação, servido o rol de medidas do art. 101, como norte e paradigma na intervenção dos atores dos Sistemas de Proteção e Justiça da Infância e Juventude.

Antes ainda de adentrar o tema central do presente estudo, cabe relembrar o conteúdo de outros importantes dispo-

volvem as relações sociais entre adultos. Note-se que há verdadeira preferência pela adoção do critério teleológico ou sociológico de interpretação, que segundo Flavio Tortuce, 'busca interpretar de acordo com a adequação da lei ao contexto da sociedade e aos fatos sociais' (Rossato, Luciano Alves. Estatuto da Criança e do Adolescente Comentado. São Paulo: Revista dos Tribunais, 2010, p. 99) 
sitivos do Estatuto, que reforçam a tese da proposital abertura concebida pelo legislador à flexibilização da sua interpretação. Um deles é o art. 99, que permite que as medidas de proteção possam ser aplicadas isoladamente, cumulativamente, assim como substituídas a qualquer tempo. ${ }^{11}$

Com o advento da Lei n. 12.010/09 (profanamente denominada "Lei de Adoção"), o Estatuto da Criança e do Adolescente também conta com princípios expressos de regência, previstos no art. 100, parágrafo único. São doze itens, interessando para o presente estudo o do interesse superior da criança e do adolescente, da proporcionalidade e da oitiva obrigatória e participação. Não que se queira aqui pretender que os demais não sejam importantes para o tema em análise, mas os mencionados princípios já se bastam.

No art. 100, parágrafo único, IV, do Estatuto, há entendimento de que o interesse superior da criança e do adolescente consistiria na intervenção prioritariamente aos interesses e direitos da criança e do adolescente, sem prejuízo da consideração que for devida a outros interesses legítimos no âmbito da pluralidade dos interesses presentes no caso concreto.

Afora algumas críticas ao princípio do superior interesse, que, reconheça-se, se inadequadamente interpretado, poderia conduzir o atores do sistema de justiça a uma "atuação discricionária”, próxima daquela que se impunha sob a égide do Código de Menores $^{12}$, sua aplicação sob a égide de um reconhecido

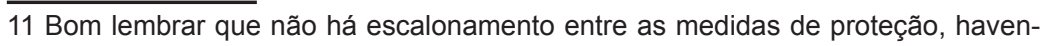
do apenas o "resguardo" daquelas consideradas "reserva de jurisdição", quais sejam: a) o acolhimento institucional; b )a inclusão em programa de acolhimento familiar; c) a colocação em família substituta.. Tais medidas somente poderão ser aplicadas pela autoridade judiciária. As demais, de regra, devem ser aplicadas, preferencialmente, pelo Conselho Tutelar, sendo a atuação da autoridade judiciária subsidiária.

12 Ensina João Batista Costa Saraiva: "Por conta da indeterminação deste princípio deve ser interpretado em face dos direitos declarados. Somente será Superior Interesse o cumprimento dos direitos declarados, vg. Legalidade, ampla defesa, contraditório, devido processo, etc. Não se cogita em um princípio aberto, sujeito à interpretação ampla, sob pena de transformar-se no "cavalo de troia do menorismo" dentro do sistema do Estatuto. (Compêndio de Direito Penal Juvenil - Adolescente e Ato Infracional. Porto Alegre: Livraria do Advogado, 2010, p. 77) 
sistema de garantias, emancipatório e de promoção da criança e do adolescente a condição de protagonistas e não de meros coadjuvantes dos processos decisórios dos rumos de suas vidas, inclusive os judiciais, representa evidente evolução, ou melhor, autorização para a evolução do direito da criança e do adolescente que, ao contrário do que muitos ainda acreditam, não teve seu "marco final" com a publicação do Estatuto da Criança e do Adolescente em 13 de julho de 1990.

A promoção de tal princípio a orientador, expresso no Estatuto da Criança e do Adolescente, reforça a condição de crianças e adolescentes como sujeitos de direitos (art. 100, I), portadores de capacidades, desejos, interesses, numa certa proporção, até discernimento (o art. $6^{\circ}$, os define como pessoas em condição peculiar de desenvolvimento!), etc.

Não por outro motivo, estabeleceu o legislador também como princípios orientadores a proporcionalidade e oitiva obrigatória e participação da criança e do adolescente nos processos decisórios, devendo a sua opinião ser devidamente considerada pelos atores ${ }^{13}$ do Sistema de Justiça quando da definição das medidas a serem promovidas em seu favor.

Ocorre que, ao mesmo tempo em que o Estatuto estabelece que a tomada de decisões a respeito de direitos de crianças e adolescentes deve resultar de um processo flexível, adequado à realidade, há, naturalmente evidente preocupação em se limitar a atuação discricionária e ilimitada dos atores.

Evidentemente, não se deseja que a previsão do superior interesse como princípio refente das medidas de proteção

13 Nos dizeres de Alexandre de Moraes da Rosa (in Introdução Crítica ao Ato Infracional. Princípios e Garantias Constitucionais, p. 01): "Emprega-se o termo 'ator jurídico em vez de 'operador jurídico' por se entender que o primeiro pressupõe a participação nos fatos pelo intérprete, inserido no mundo da vida (sujeito-sujeito), enquanto o segundo facilita a objetivação e o seu distanciamento. As formas clássicas de interpretação do Direito propostas pela dogmática jurídica apresentam o interprete dissociado da realidade social (sujeito-objeto), envolto numa realidade virtual, favorecendo, com isso, a comodidade e o (des)compromisso ético (Dussel) das decisões." 
converta-se numa repetição do art. 8º, do Código de Menores ${ }^{14}$, que permitia à autoridade judiciária outras medidas de ordem geral, que, ao seu prudente arbítrio (eram estes os termos utilizados no referido dispositivo!), se demonstrarem necessárias à assistência, proteção e vigilância ao menor.

No entanto, repita-se, apesar da preocupação dos atores do sistema de justiça em evitar uma "discricionariedade desenfreada", com a aplicação se "soluções caseiras" desprovidas de qualquer delineamento por parte do Estatuto da Criança e do Adolescente $^{15}$, tal atuação não pode se distanciar da realidade, não pode se distanciar, conforme já dito, do "bem da vida”. Não traria vantagem alguma a crianças e adolescentes a implementação "engessada" do Estatuto, desconsideradora de suas reais necessidades, que somente poderiam ser verificadas adequadamente conforme o caso concreto.

A despeito do que até agora observou-se, pode-se constatar, facilmente, a forte resistência por parte do Judiciário acerca daquelas que podem ser consideradas "adoções peculiares”, quais sejam, as que não se enquadram, numa referência a Hans Kelsen, na "moldura estatutária da adoção", que tem como principais limites objetivos, a impossibilidade de adoção formulada pelos avós e irmãos dos adotantes, a adoção unilateral formulada permitida apenas ao cônjuge ou companheiro do genitor da criança, a diferença de idade entre adotante e adotando, fixada no mínimo em dezesseis anos, e a impossibilidade de adoção por um casal separado quando o estágio de convivência não tenha se iniciado durante o período de convivência do casal.

Quanto à primeira espécie de “adoção peculiar”, qual seja, aquela formulada por ascendentes ou irmãos do adotando,

14 Lei n. 6.697/1979 (Código de Menores): "Art. $8^{\circ} \mathrm{A}$ autoridade judiciária, além das medidas especiais previstas nesta Lei, poderá, através de portaria ou provimento, determinar outras de ordem geral, que, ao seu prudente arbítrio, se demonstrarem necessárias à assistência, proteção e vigilância ao menor, respondendo por abuso ou desvio de poder."

15 Ao contrário da figura do "Juiz de Menores", o "Juiz da Infância e Juventude", não mais se confunde com uma "bonus pater familiae". 
parte da doutrina, como Galdino Augusto Coelho Bordallo, estabelece tais hipóteses como casos únicos de "impedimento total à legitimidade para adotar" ${ }^{16}$.

As justificativas para tais vedações vão desde "evitar inversões e confusões nas relações de parentesco", blindar a família de "alterações das relações de afeto", "impedir um desequilibrio às suas sadias relações". Valter Kenji Ishida tem o disparate de afirmar que tal hipótese de adoção seria vedada "já que a intenção [na adoção] é o rompimento dos vínculos naturais de filiação e parentesco." ${ }^{\prime 17}$

Galdino Augusto Coelho Bordallo afirma, categoricamente: "Como se vê, haveria alteração de todos os graus de parentesco, o que tumultuaria demasiadamente as relações familiares. Foi, certamente, pensando neste tumulto, entre outras coisas, que o legislador criou o impedimento." 18

Ocorre, no entanto, que tais justificativas primeiramente, não se coadunam com os princípios do Estatuto da Criança e do Adolescente, principalmente em relação ao instituto da adoção, já que tal medida deve trazer, nos termos do art. 43 do Estatuto da Criança e do Adolescente, reais vantagens para a criança e fundar-se em motivos legítimos.

Ora, estabelecer-se uma "vedação total" (palavras de Galdino Augusto Coelho Bordallo), fundando-se no "equilíbrio das SADIAS relações familiares” (a caixa alta foi proposital!) diga-se: já havia algum tempo que não lia tão vaga afirmação! - não parece em conformidade com o princípio da proteção integral e absoluta prioridade previstos no Estatuto.

Tais, "justificativas" não se legitimam quando confrontadas aos casos concretos. Veja-se caso já atendido pelo autor

16 Curso de Direito da Criança e do Adolescente - Aspectos Teóricos e Práticos", coordenadora Kátia Regina Ferreira Lobo Andrade Maciel, Ed. Lúmen Júris: Rio de Janeiro, 2006, p. 264.

17 Estatuto da Criança e do Adolescente: Doutrina e Jurisprudência/Comentários. Ishida. Válter Kenji. $12^{a}$ edição. São Paulo. Editora Atlas S.A. p. 88

18 Curso de Direito da Criança e do Adolescente - Aspectos Teóricos e Práticos", coordenadora Kátia Regina Ferreira Lobo Andrade Maciel, Ed. Lúmen Júris: Rio de Janeiro, 2006, p. 264. 
do presente artigo científico, que se encontra ainda em fase de instrução. Uma senhora cria seu irmão biológico há mais de oito anos. O menino conta, à época em que a irmã aciona a Justiça da Infância e Juventude, com nove anos de idade. A diferença de idade entre o menino e a irmã passa dos trinta anos. Não foram criados juntos, nem são filhos da mesma mãe.

Tomando-se a risca os termos do Estatuto da Criança e do Adolescente, a relação de mãe e filho que legitimamente se estabeleceu jamais poderia ser formalizada e, ainda que o desejo dos dois fosse apenas promover ao plano jurídico a filiação de fato, o máximo que a Justiça da Infância e Juventude lhes poderia oferecer seria uma Guarda, ou, talvez, uma Tutela. Tais, institutos, no entanto, jamais "refletiriam" a realidade.

E é da leitura comparada das Leis n. 3.071/1916 (Código Civil de 1916), 6.697/1979 (Código de Menores), 10.406/2002 (Código Civil Atual) e do próprio Estatuto da Criança e do Adolescente, que se acaba observando que a manutenção, ou melhor, afirmação de uma "vedação total" à adoção por ascendentes e irmãos não tem como fundamento a absoluta prioridade, proteção integral, ou o melhor interesse de crianças ou adolescentes.

O objetivo de tal "vedação total" é, na realidade, de proteção aos demais herdeiros, ou seja, meramente patrimonial ${ }^{19}$. Nada tem a ver, portanto, com os princípios norteadores do Estatuto. O propósito é única e exclusivamente o de "proteger" os demais herdeiros e não a criança ou adolescente adotando. Por este motivo as justificativas a tal vedação, apresentadas pelos doutrinadores, são tão rasas, tão vagas.

É a antiga lógica do direito de se criar justificativas para determinados institutos, criados em outros momentos histó-

19 O próprio Galdino Augusto Coelho Bordallo afirma que "Com esta possibilidade de adoção surgiriam problemas de novos impedimentos matrimoniais, com a manutenção dos impedimentos anteriormente existentes, além de questões sucessórias." (in Curso de Direito da Criança e do Adolescente - Aspectos Teóricos e Práticos", coordenadora Kátia Regina Ferreira Lobo Andrade Maciel, Ed. Lúmen Júris: Rio de Janeiro, 2006, p. 264.) 
ricos, ou de cuja origem ninguém se recorda, por meio de "filosofismos baratos". Ou não causa desconforto (ou não seria desconfiança?) àquele que lê: "Caso fosse permitida a adoção por esses parentes, haveria um verdadeiro tumulto nas relações familiares, em decorrência da alteração dos graus de parentesco." 20 Como se o Estatuto da Criança e do Adolescente não estimulasse a adoção, na forma direta (intuito personae) no seio da própria família extensa (art. 50, § 13)! Eventual pleito de adoção formulado por um tio também não "tumultuaria" as relações familiares?

Ocorre que, até a edição do Estatuto da Criança e do Adolescente a filiação adotiva era tratada com imenso preconceito, até mesmo na legislação. Os dispositivos que tratavam do instituto, em inúmeros aspectos, tornavam a filiação adotiva como secundária, ou inferior à natural. E, se o Estatuto representou, de certa maneira, uma evolução conceitual acerca do instituto da adoção, alguns "retalhos tutelares", incoerentes com um sistema de proteção que se pretende, ainda persistem em seu corpo, mormente se considerados como regras irredutíveis, inafastáveis.

Evidentemente, a adoção tendo à época como principal diploma o Código Civil de 1916, patriarcal, patrimonialista, não tinha como principal destinatário de seus regramentos a criança ou adolescente (menor) adotando. Do contrário, a norma mais protegia os LEGÍTIMOS (caixa alta também não foi por acaso!) familiares dos adotantes, que poderia ver-se prejudicados pelo ingresso de mais um sucessor concorrente.

Tanto é verdadeira tal afirmação que o art. 368 estabelecia que somente os maiores de cinquenta anos, sem prole legítima, ou legitimada, poderiam adotar. $\mathrm{O}$ mesmo art. 368 determinava que só os maiores de 30 (trinta) anos poderiam adotar. Ninguém poderia adotar, sendo casado, senão decorridos 5 (cinco) anos após o casamento.

20 Curso de Direito da Criança e do Adolescente - Aspectos Teóricos e Práticos", coordenadora Kátia Regina Ferreira Lobo Andrade Maciel, Ed. Lúmen Júris: Rio de Janeiro, 2006, p. 264. 
Já o vínculo de adoção era absolutamente precário, podendo ser dissolvido por convenção das partes ou em razão de ingratidão do adotando com o adotante (art. 374). Pior ainda era a regra do parentesco que se estabelecia com a adoção, que o limitava ao adotante, não se estendendo aos demais parentes, mantendo-se apenas os impedimentos matrimoniais.

A filiação natural estava tão protegida contra a adoção que o art. 377 estabelecia: "A adoção produzirá os seus efeitos ainda que sobrevenham filhos ao adotante, salvo se, pelo fato do nascimento, ficar provado que o filho estava concebido no momento da adoção." O filho adotivo não era bem vindo mesmo na vigência do Código Civil do senhor Clóvis Beviláqua!

Finalmente estabelecia o Código Civil de 1916 que quando o adotante tivesse filhos legítimos, legitimados ou reconhecidos, a relação de adoção não envolveria a de sucessão hereditária. Determinavam, ainda, que os direitos e deveres que resultassem do parentesco natural não se extinguiriam pela adoção, exceto o pátrio poder, que seria transferido do pai natural para o adotivo. Bom lembrar que neste período a adoção se concretizava por escritura pública!

Seguindo lógica não menos preconceituosa e de garantia do patrimônio dos sucessores, o Código de Menores, Lei n. 6.697/1979, ao tratar da "Colocação em Lar Substituto" prevê, como espécies a delegação do pátrio poder, guarda, tutela, adoção simples e adoção plena.

Somente a adoção plena atribuía o status de filho ao adotado. Em regra, somente caberia tal espécie de adoção caso a criança fosse menor de sete anos de idade ou, se mais velho, já estivesse sob a guarda dos adotantes. Se o pedido fosse formulado por viúvo, ou viúva, deveria haver prova de que já convivessem durante, no mínimo, três anos em vida do outro cônjuge.

Já o Estatuto da Criança e do Adolescente, decorrência da necessária regulamentação do novo paradigma constitucional da proteção à infância e adolescência (CFRB, art. 227), rompeu com uma série de preconceitos acerca do instituto da adoção, 
mantendo, no entanto, alguns regramentos, como, por exemplo, as regras do art. 46, que busca deixar a origem de tal medida no mais absoluto sigilo, para que a filiação se pareça com a natural, que não passam de "resíduos" do sistema anterior ${ }^{21}$.

A questão da permissão, ou não, de adoção por ascendentes ou irmãos da criança ou adolescente foi amplamente discutida na década de oitenta, já que nem o Código Civil de 1916, nem o Código de Menores tratavam expressamente de tal vedação. Não houve uma corrente prevalente ou que tenha gerado maior convencimento. ${ }^{22}$

Tanto é assim que, já sob a vigência do Estatuto, em precedente do Superior Tribunal de Justiça, ao considerar juridicamente impossível a adoção por ascendentes e irmãos, efetuando uma interpretação literal da lei, o Ministro Nilson Naves, que foi voto vencedor, manifestou certo desconforto, tendo assim se posicionado:

Talvez a proibição seja prejudicial, tratando-se de caso como o destes autos, onde o menor, conforme anotou a sentença, 'tem os requerentes como pais', e que, 'sendo o adotando um menor esclarecido, cursando a sétima série do $1^{\circ}$ grau, sabe perfeitamente a importância que representa para ele esta adoção', mas a lei de tão expressa, não me permite,

21 Engana-se quem crê que o Estatuto promoveu um absoluto rompimento com o modelo tutelar que o antecedeu. Não que se pretenda retirar o mérito de tal lei, que, de fato, apresentou um novo modelo de proteção à infanto-adolescência, o Estatuo manteve uma série de regramentos ainda tutelares, como, por exemplo, aquele que delega à autoridade judiciária certa "competência normativa" para regulamentação de espetáculos/eventos em que ocorra a participação de criança ou adolescente. Tais dispositivos somente ganham força quando da interpretação sistêmica da lei, levando-se em consideração os princípios que norteiam o Estatuto, mormente do da absoluta prioridade.

22 "A jurisprudência era mansa e tranquila quando à possibilidade de adoção por avós (RT, 611:171, 569:77; 558/222), ou mesmo por irmão (RT, 642:104), o que não deixava de trazer inconveniências nas relações de parentesco estabelecidas pela adoção, inclusive com a alteração do registro inicial. Contudo, agora o Estatuto veda expressamente a adoção por avós ou irmãos, pois a adoção atribui a condição de filhos ao adotando, com os mesmo direitos e deveres, inclusive sucessórios, desligando-o de qualquer vínculo com os pais e parentes, salvo impedimentos matrimoniais (art. 41)" (in "Estatuto da Criança e do Adolescente, Saraiva, pg. 54) 
data venia, solução outra senão a de dar razão ao recorrente. Olhem que não sou positivista, pois procuro sempre me agarrar mais ao espírito do que à letra da lei. Longe de mim a literalidade, até porque a lei e com não não é mais do legislador, mas e principalmente do seu intérprete e aplicador, como somos nós, os juízes. (REsp - 76.712/GO)

Salvo melhor juízo, não parece de acordo com os preceitos do Estatuto da Criança e do Adolescente o estabelecimento de vedações totais, inafastáveis à adoção. Não se quer aqui dizer que tais casos, de adoção por irmãos ou ascendentes, sempre representem reais e indiscutíveis vantagens aos adotandos. Reconhecer tais casos como vedação absoluta, sob a justificativa de que haveria confusão nas relações familiares/hereditárias, não parece adequado.

Parece adequado concluir que a adoção, assim como qualquer outra forma de colocação em família substituta, deve refletir a realidade já estabelecida. Diga-se: o que estaria mais de acordo com os interesses da criança, verdadeiro destinatário da medida, ter em seu registro de nascimento o nome da pessoa que reconhece como pai e mãe, ou ver protegido o "equilíbrio de suas relações familiares"?

Estaria a criança interessada na manutenção de tal "equilíbrio"? Tais "vínculos familiares" seriam mais importantes que o interesse da criança em ter o nome daquela que tem como mãe em seu registro de nascimento? Se o propósito é a manutenção dos vínculos familiares, por que razão o Estatuto estimula a adoção pela família extensa (art. 50, § 13)?

Parecem não se dar conta os defensores da manutenção da vedação à demandas formuladas por avós ou irmãos que toda espécie de adoção depende da formação da filiação socioafetiva, que somente poderá ser aferida pelas equipes técnicas das Varas da Infância e Juventude. ${ }^{23}$ Se o vínculo socioafetivo estabelecido

23 Ensina Arruda Alvim: "há faltos que exigem conhecimentos especias, de que o juiz normalmente é carecedor, tornando indispensável o concurso de pessoa habilitada, para subsidiar o juiz. (in.: Tratado de direito processual civil. 2. ed. São Paulo: Revista dos Tribunais) 
entre avô e neto, ou entre irmãos, não corresponde ao biológico, beira à hipocrisia, ou falta de bom senso, impedi-los de, legalmente, formalizar a adoção, limitando-os a se contentarem com uma guarda ou tutela.

Ora, se os pareceres da equipe técnica da Justiça da Infância e Juventude posicionarem-se favoravelmente ao estabelecimento do vínculo socioafetivo de filiação - e, sim, quem deve dizer isso são os profissionais da psicologia e do serviço social, já que isto não é tarefa para os profissionais do direito! - não cabe ao Poder Judiciário denegar tal propósito. ${ }^{24}$

Conforme insistentemente antecipado, o próprio Estatuto da Criança e do Adolescente, no art. 6º , repetindo o 5º da Lei de Introdução ao Código Civil, estabelece que na sua interpretação levar-se-ão em conta os fins sociais a que ela se dirige, as exigências do bem comum, os direitos e deveres individuais e coletivos, e a condição peculiar da criança e do adolescente como pessoas em desenvolvimento.

Uma lei, em regra, não é composta de único artigo e, ainda que se reconheça a literalidade do dispositivo que veda a espécie de adoção que ora se pretende, tratando-se de um resquício tutelar/menorista, nada mais adequado que a interpretação sistêmica e social do Estatuto para, verificar se a representa, nos termos do art. 43 do Estatuto da Criança e do Adolescente, reais e indiscutíveis vantagens para o adotando.

O mesmo se diga da resistência à adoção por pretendentes que ainda não tenham alcançado a diferença de idade de dezesseis anos em relação ao adotando, em decorrência da regra prevista no art. $42, \S 3 \circ$, do Estatuto, o qual se transcreve:

Art. 42. Podem adotar os maiores de vinte e um anos, independentemente de estado civil. (...)

$24 \mathrm{Na}$ ementa do Recurso Especial n. 889.852-RS, fica clara a deferência do Ministro Relator Luiz Felipe Salomão à posição da equipe técnica: "Existência de consistente relatório social elaborado por assistente social favorável ao pedido da requerente, ante a constatação da estabilidade da família. Acórdão que se posiciona a favor do pedido, bem como parecer do Ministério Público Federal pelo acolhimento da tese autoral." 
3० $\mathrm{O}$ adotante há de ser, pelo menos, dezesseis anos mais velho do que o adotando.

Não obstante seja indiscutível que a diferença de idade entre adotante e adotando fixada em dezesseis anos decorre de critério bastante coerente, estabelecido de acordo com a idade núbil prevista no art. $1.517^{25}$, deve-se ter em mente a finalidade protetiva do Estatuto da Criança e do Adolescente. As normas ali contidas devem ser interpretadas a favor da criança visando propiciar o seu bem-estar físico, mental, emocional, educacional e etc.

É importante, ainda, se evidenciar que a finalidade da norma prevista no art. 42, § 3o, do Estatuto, e igualmente reproduzido no art. 1.619, do Código Civil, é se evitar que o adotado pudesse ter a idade muito próxima à do adotante, somado ao aspecto psicológico e educacional, onde, em regra, a diferença de idade já proporcionaria ao adotante mais maturidade e capacidade para desempenhar tal papel.

Parece coerente que, por exemplo, se a demanda for formulada por um casal, tendo um deles cumprido o requisito da diferença mínima de idade e o outro estando muito próximo do limite legal, o deferimento da medida em favor de ambos. O próprio Estatuto, em sua redação original, abria exceção ao critério de idade quando se tratasse de adoção formulada por casal, ao estabelecer que " $a$ adoção por ambos os cônjuges ou concubinos poderá ser formalizada, desde que um deles tenha completado vinte e um anos de idade, comprovada a estabilidade da família" (art. 42, § 2, com redação anterior à Lei n. 12.010/09).

Referida norma se repetiu no Código Civil e passou a ser utilizada como parâmetro entre 2002 e 2009, quando entrou em vigor a Lei n. 12.010/09. O art. 1.618, parágrafo único, do Código Civil estabelece que "a adoção por ambos os cônjuges ou companheiros poderá ser formalizada, desde que um deles tenha completado dezoito anos de idade, comprovada a estabilidade da família".

25 Art. 1.517, do Código Civil: "O homem e a mulher com dezesseis anos podem casar, exigindo-se autorização de ambos os pais, ou de seus representantes legais, enquanto não atingida a maioridade civil." 
Ora, respeitado o princípio do melhor interesse (art. 100, IV, do Estatuto), parece cabível, em caráter excepcional, quando um dos cônjuges já possui a diferença mínima de idade, requisito à adoção, a interpretação finalística da norma (art. 42, § 3o $\mathrm{X}$ arts. 1.618 do CC), o seu deferimento. Assim, se há previsão legal - agora somente no Código Civil - que excepciona a necessidade de ser o adotante maior que dezoito, igualmente poderia ser aplicada para a regra que impõe a diferença de dezesseis anos.

Em verdade a doutrina já se posiciona assim, conforme a lição de Maria Helena Diniz: "Na adoção o adotante deve ser, para que possa bem desempenhar o exercício do poder familiar (RT, 500:219), dezesseis anos mais velho que o adotado menor. Impossivel seria admitir um filho de idade igual ou superior à do pai, seja ele maior ou menor. Se o adotante for um casal, bastará que um dos consortes seja dezesseis anos mais velho que o adotado." 26

No mesmo sentido, o seguinte precedente:

CIVIL E PROCESSO CIVIL. ADOÇÃO. ECA. DIFERENÇA DE IDADE ENTRE O ADOTANTE E O ADOTADO. MÍNIMO LEGAL. MITIGAÇÃO DOS RIGORES DA LEI EM BENEFÍCIO DO MENOR.1. QUANDO O ESTATUTO EXIGE A DIFERENÇA MÍNIMA DE IDADE ENTRE O ADOTANTE E O ADOTADO DE 16 (DEZESSEIS) ANOS, FÁ-LO SOMENTE PARA ASSEGURAR O PAPEL PATERNO ASSUMIDO, O QUE JÁ RESTOU CLARO, QUANDO SE FALA DOS FORTES LAÇOS AFETIVOS QUE OS UNEM, E QUANDO A INICIAL DIZ QUE O MENOR O RESPEITA COMO A UM PAI E INCLUSIVE ASSIM O CHAMA.2. ASSEVERO QUE, NESTE CASO, EM QUE A DIFERENÇA DE IDADE PERFAZ 15 ANOS E 3 MESES, PORTANTO O ADOTANTE QUASE ATINGE A IDADE MÍNIMA, CONSIDERO SER CONVENIENTE AOS INTERESSES DO MENOR, ANTE A POSSIBILIDADE DE

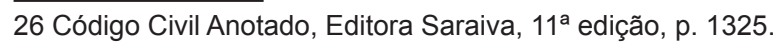


FORNECER AO ADOTANDO AMBIENTE FAMILIAR SAUDÁVEL, PROPÍCIO A SEU DESENVOLVIMENTO COMPLETO. (APL 20000130017887 DF, Relator: SILVÂNIO BARBOSA DOS SANTOS, Data de Julgamento: 21/10/2002, 2a Turma Cível, Data de Publicação: DJU 12/02/2003 Pág.: 37)

Saliente-se, finalmente, que a autoridade judiciária deve pautar suas decisões conforme o melhor interesse da criança e do adolescente. Veja-se:

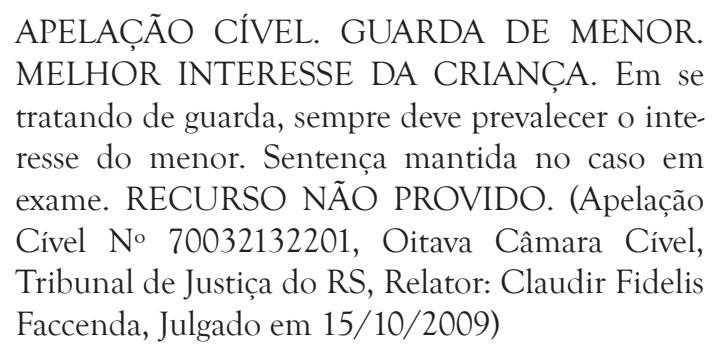

No mais, no sentido de relativizar o regramento da diferença de idade entre adotante e adotando, que conforme já adiantado, tem como pressuposto a idade núbil prevista no Código Civil, claramente poder-se-ia considerar, ao menos, a diferença de quatorze anos de idade, em que, excepcionalmente é permitido o casamento. ${ }^{27}$

\section{CONCLUSÃO}

Seguindo a mesma lógica que se estabeleceu no correr do presente artigo, parece conveniente observar que as mencionadas "adoções peculiares", quaisquer que sejam, quando "batem à porta do Judiciário" depende de soluções dinâmicas e desprovidas de formalismos exagerados.

Por esta razão, as adoções formuladas por cônjuges separados ou divorciados, sem que o estágio de convivência tenha

27 Art. 1.520. Excepcionalmente, será permitido o casamento de quem ainda não alcançou a idade núbil (art. 1517), para evitar imposição ou cumprimento de pena criminal ou em caso de gravidez. 
se iniciado na constância da sociedade conjugal, ou mesmo adoções unilaterais formuladas por pessoas que jamais tenham contraído matrimônio ou mantido união estável, caso representassem reais vantagens ao adotando e se fundassem em motivos legítimos, não deveriam ser consideradas juridicamente impossíveis.

Do contrário, em conformidade com o art. 43 do Estatuto da Criança e do Adolescente, "regra de ouro da adoção" e, seguindo o critério de teleológico ${ }^{28}$ ou sociológico de interpretação dos dispositivos do Estatuto da Criança e do Adolescente, trazido pelo art. $6^{\circ}$, casos de "adoções peculiares" devem ser apreciados pelo Poder Judiciário e, caso representem reais vantagens ao adotando e fundamentem-se em motivos legítimos, não representando qualquer prejuízo aos interessados, devem ser deferidos.

A atuação do profissional do direito na seara do Direito da Criança e do Adolescente deve sempre ter em vista os interesses de seus destinatários por natureza e não o resguardo de determinadas regras do Estatuto que, se "lidas" (e não "analisadas") isoladamente representam impedimentos à justa concretização de certas garantias, como, por exemplo, o pleno exercício do direito à convivência familiar e comunitária, conforme o dado da realidade que se impõe.

Se o propósito das regras da adoção continuar sendo o de "blindar" uma suposta "sucessão legítima". Se este é o interesse prevalente, e não o de reforçar vínculos socioafetivos já estabelecidos entre crianças e seus pais de fato, então os princípios da proteção integral, absoluta prioridade, do melhor interesse, assim como a declaração de que crianças e adolescentes são sujeitos e portadores de direitos não passariam de engodo, de mera hipocrisia por parte do legislador e operadores do direito.

28 Conforme ensinamentos de Válter Kenii Ishida, in Estatuto da Criança e do Adolescente. Doutrina e Jurisprudência (pg. 11): "Neste sentido, o STJ: "Na linha de precedente desta Corte, a legislação que dispõe sobre a proteção à criança e ao adolescente proclama enfaticamente a especial atenção que se deve dar aos seus direitos e interesses e à hermenêutica valorativa e teleológica na sua exegese" (RSTJ 120/341) 
Abstract: This article present the analysis of the legal possibility, as teleological interpretation of "peculiar adoptions" at first glance prohibited by the Statute of Children and Adolescents. The survey, which took into account the doctrine and jurisprudence concerning the right of children and adolescents, evidence of such incompatibility seals if deemed "total" ("absolute") with the rest of the context of the current law, especially when considered full protection, the best interests and peculiar condition of subjects as developing interpretive north.

Keywords: Adoption. Extended family. Unilateral adoption. Teleological interpretation.

\section{REFERÊNCIAS}

ALVIM, Arruda. Tratado de direito processual civil. 2. ed. São Paulo: Revista dos Tribunais.

CURY, Munir et al (coord.). Estatuto da Criança e do Adolescente Comentado, 11. ${ }^{a}$ ed., São Paulo: Malheiros, 2010

CÓDIGO CIVIL, Col. Saraiva, 60ed.Saraiva, 2009

DIAS, Maria Berenice, cf. Manual de Direito das Famílias. 5. Ed. São Paulo: RT, 2009

ESTATUTO DA CRIANÇA E DO ADOLESCENTE, Col. Saraiva de Legislação,18 ed.:Saraiva, 2011

FARIA, Cristiano Chaves de; ROSENVALD, Nelson. Direitos das Famílias.3.ed. Rio de Janeiro: Lumen Juris, 2011

GONÇALVES,Carlos Roberto. Direito Civil Brasileiro:Direito de Família, 6. ed. São Paulo: Saraiva, 2009, vol. VI

ISHIDA, Válter Kenji. Estatuto da criança e do adolescente: doutrina e jurisprudência. 12. ed. São Paulo: Atlas, 2010

MACIEL, Kátia. Curso de Direito da Criança e do Adolescente Aspectos Teóricos e Práticos, coordenadora Kátia , Ed. Lúmen Júris: Rio de Janeiro, 2006. 
PIZZOL, Alcebir Dal. Estudo social ou perícia social? Um estudo teóricoprático na justiça catarinense. Florianópolis: Insular, 2005.

ROSA, Alexandre Morais da. Introdução Crítica ao Ato Infracional:

Princípios e Garantias Constitucionais. Rio De Janeiro: Lumen Juris, 2007.

ROSSATO, Luciano Alves; LÉPORE, Paulo Eduardo; CUNHA, Rogério Sanches. Estatuto da criança e do adolescente comentado. São Paulo: Revista dos Tribunais, 2010.)

SARAIVA, João Batista Costa. Compêndio de Direito Penal Juvenil. Adolescente e Ato Infracional. Porto Alegre: Livraria do Advogado, 2010. 